\title{
Research on the Influence of Investor Concern on the Market Performance of Coal Listed Companies
}

\author{
Hongxia Li, Xu Yang \\ School of Management, Xi'an University of Science and Technology, Xi'an, China \\ Email: 583751822@qq.com
}

How to cite this paper: Li, H.X. and Yang, $\mathrm{X}$. (2019) Research on the Influence of Investor Concern on the Market Performance of Coal Listed Companies. Open Access Library Journal, 6: e5497. https://doi.org/10.4236/oalib.1105497

Received: May 23, 2019

Accepted: July 19, 2019

Published: July 22, 2019

Copyright $\odot 2019$ by author(s) and Open Access Library Inc.

This work is licensed under the Creative Commons Attribution International License (CC BY 4.0).

http://creativecommons.org/licenses/by/4.0/

\section{(c) (7) Open Access}

\begin{abstract}
Since the beginning of the 21st century, the stock market has experienced many outbreaks of bull market, and stocks have gradually entered the public's field of vision from a small investment field. In the era of big data, how can investors make correct information from a large amount of information? The choice becomes the most critical issue. This paper selects 17 listed companies in the coal industry in 2018 as the research object, and uses Baidu Index as the research index of investor attention, empirically testing the impact of investment attention on the market performance of coal listed companies. The study found that: first, the current investor attention significantly affected the stock returns and liquidity of the current coal listed companies; second, the investor attention of the lag period and the current stock returns of coal listed companies were significantly negative. And the investor attention in the lag period is still significantly positively correlated with the stock liquidity of the current coal listed companies.
\end{abstract}

\section{Subject Areas}

Business Ethics and Corporate Social Responsibility, Business Finance and Investment, Corporate Governance, Managerial Economics, Marketing, Risk Management

\section{Keywords}

Investor Attention, Market Performance, Baidu Index

\section{Introduction}

In the past research on investors' attention, it is mainly divided into two parts: 
the theory of psychology and the theory of behavioral finance [1]. The psychology-related theories mainly include attention theory and attention distribution theory; and the behavior finance related theory mainly includes effective market theory and behavioral finance theory.

Attention refers to the cognitive process in which an individual selectively obtains information from the outside world, can attract attention, has relative discrimination, and instinctively filters out some invalid information [2]. When investors face thousands of stocks in the stock market, they simply can't have enough energy to pay attention to each stock. At this point, the role of attention theory is highlighted. The most important feature of attention is selectivity, because people's energy is limited. In the face of complicated news, it is necessary to screen out valuable information for individuals, focus their attention on this, and ignore those that are invalid [3]. Therefore, this paper introduces the theory of information attention distribution.

The theory of attention distribution says that individuals have a finite amount of attention; the subject can generally pay attention to a variety of information at the same time. When the cognitive resources of the information exceed the cognitive ability of the subject, they cannot be performed at the same time. The brain then makes choices about the allocation of attention [4].

The effective market theory, also known as the efficient market hypothesis, is a milestone in the modern capital market theory system. It lays an important foundation for the establishment of many modern financial investment theories such as capital asset pricing model and arbitrage pricing theory. Efficient market theory states that all information available in financial markets can be expressed through the price of financial assets, and investors cannot use any known information to obtain additional revenue [5].

Behavioral finance theory emerged in the 1980s on the basis of modern financial theory. It broke away from the constraints of the original rational framework, explained market behavior from the perspective of human beings, and fully considered the role of investors' psychological factors. Explaining the various behaviors in the financial market provides a new perspective.

Behavioral finance theory is formed on the basis of psychological research results. The theory takes the investor's actual decision-making psychology as the starting point, and studies the influence of investors' investment decision-making behavior on market price. Behavioral finance theory takes into account investor decision-making. The diversity of psychology breaks through the original modern financial theory and only pays attention to the characteristics of the optimal decision-making model. The theory holds that the rational investment decision-making model is only the assumption of the actual investment decision-making model that determines the price change of the stock market [6]. The study of investor behavior in the financial market has changed from "how to make decisions" to "how to make decisions", making research closer to reality. Therefore, although modern financial theory is still the best description of mar- 
ket price so far, this paper studies investor behavior from the perspective of behavioral finance, which has certain research significance.

\section{Research Hypothesis}

\subsection{Investor Attention to the Impact of Stock Yields}

Considering that investors' attention is limited, investors will allocate limited resources of interest to the stock information they are interested in. Therefore, when an investor searches for information about a stock, it indicates that investors are only paying attention to the stock and its final investment decision will be related to the stock information that it is concerned about [7]. Therefore, we can think that it is the investor's search behavior that affects his investment decision-making behavior, which ultimately affects the stock price movement. In other words, the number of searches for stocks can directly reflect the degree of attention investors pay to stocks, so that investors make investment decisions and have an impact on the stock market. Therefore, this paper proposes hypothesis 1:

H1: Investor attention is positively correlated with the stock returns of coal listed companies.

\subsection{The Impact of Investor Attention on Stock Liquidity}

In the actual situation, the stock market's gains and losses are realized by trading stocks. Therefore, investors' attention will affect the stock's return rate and also affect the stock's liquidity. From the analysis of the influence mechanism of investors' attention on stock liquidity, it can be known that when investors receive information from the market, due to the driving force of attention, investors will be encouraged to trade frequently on the stock market [8]. That is to say, the increase in investor concerns will lead to changes in stock market liquidity. Therefore, this paper proposes hypothesis 2:

$\mathrm{H} 2$ : Investor attention is positively correlated with stock liquidity of coal listed companies.

\section{Research Design}

\subsection{Sample Selection}

When the former scholars studied the investment behavior caused by investors' attention, most of them chose the whole stock market or A-share market as the research object. In order to further refine the research, this paper selects the stock market performance of specific industries to conduct research. The coal industry, as China's core industry, has the first representative. Therefore, this paper selects 27 listed companies in the coal mining and selection industry as the research object, and excludes 10 listed companies whose Baidu search data is incomplete or whose stock market performance data is incomplete due to suspension of trading, and selects the remaining 17 listed companies as sample 
stocks. The samples came from the Shanghai and Shenzhen stock exchanges. This paper selects the data for the whole year from January 1, 2018 to December 31 , 2018, excluding the non-trading days such as statutory holidays and weekends. There are 243 individual trading days, so the total sample data of this study is 4131 (Table 1).

\subsection{Variable Design}

1) Explanatory variables

Considering that when an investor searches on a Baidu search engine, if he searches for the securities name of a sample company, there is a possibility that he only wants to know the basic information of the company rather than interested in the performance of the company's stock, and when investing When searching for the stock code of a sample company, it is more likely to be interested in the company's stock performance. Therefore, this paper selects Baidu Index, which uses the securities code of 17 sample companies as the keywords to search, as an explanatory variable for investigating investor attention and market performance of coal listed companies. It is expressed by Attention in empirical research.

What needs to be explained here is that due to the large number of proxy variables Baidu Index of investor attention, this paper sets its unit to 100 in empirical research.

Table 1. Abbreviations and codes of sample companies' securities.

\begin{tabular}{|c|c|c|}
\hline Number & Abbreviation & Code \\
\hline 1 & Jingyuan Coal & 000552 \\
\hline 2 & Hebei Central Energy & 000937 \\
\hline 3 & Xishan Coal and Electricity & 000983 \\
\hline 4 & Orchid Kechuang & 600123 \\
\hline 5 & Yanzhou & 600188 \\
\hline 6 & Yangquan Coal & 600348 \\
\hline 7 & Panjiang Shares & 600395 \\
\hline 8 & Shanghai Energy & 600508 \\
\hline 9 & Red Yang Energy & 600758 \\
\hline 10 & Turbine Coal & 600971 \\
\hline 11 & China Shenhua Energy & 601088 \\
\hline 12 & Datong Coal & 601001 \\
\hline 13 & Haohua Energy & 601101 \\
\hline 14 & Shanxi Coal & 601225 \\
\hline 15 & Leveling Co & 601666 \\
\hline 16 & Luan Ring Can & 601699 \\
\hline 17 & China Coal Energy & 601898 \\
\hline
\end{tabular}




\section{2) Interpreted variables}

The explanatory variables of this paper are market performance variables of coal listed companies, which are mainly divided into two parts: yield index and liquidity index.

a) Stock return rate (Return)

The variable is the change of the stocks of the 17 sample companies on each trading day, that is, the closing price of the day's closing price relative to the closing price of the previous trading day as an indicator.

Stock return $($ Return $)=($ the closing price of the stock on the day - the closing price of the previous trading day)/the closing price of the stock on the previous trading day $\times 100 \%$

b) Excess return rate (AReturn)

This variable is the difference between the current day's yield of the 17 sample company stocks minus the market's current day's yield.

Excess rate $($ AReturn $)=($ yield - market rate of return $) \times 100 \%$

c) Volume (Volume)

This variable refers to the total number of shares of the sample company that were traded on the day of the transaction to reflect the liquidity of the sample stock. Due to the large amount of stock daily trading volume, this paper sets its unit to 10 million shares in the empirical study.

d) Turnover rate (Turnover)

This indicator refers to the frequency at which sample company stocks are traded in the market, and is also used to reflect the liquidity of sample stocks.

Turnover $=$ stock volume/total number of shares issued $\times 100 \%$

3) Control variables

In the actual situation, it is not just the explanatory variable of investor attention that affects the market performance of coal listed companies. When we estimate the results based on the least squares method (OLS) of econometrics, we need to satisfy the hypothesis of Gauss Markov's theorem, so that the result of OLS estimation becomes the optimal linear unbiased estimate. One of the most important assumptions in the Gauss Markov's theorem is that the conditional mean of the random interference term $u$ is zero. Since there are some variables in reality, they can interpret $y$ and are related to other explanatory variables. If they are not added to the model as control variables, the variable will become part of the random interference term $u$, thus making the estimation result. Become a biased estimate. Therefore, combined with the overall situation of China's coal listed companies and with reference to the Fama-French three-factor model, this paper adds three control variables: market value, net assets per share and market yield.

Fama-French (1992) constructed the Fama-French three-factor model based on the capital asset pricing model, and established the market asset portfolio $\left(R_{m}-R_{f}\right)$, market capitalization factor (SMB), and book market value ratio factor (HML). The factors, through empirical research, found that a series of risk factors can explain the difference in stock returns and changes in stock returns. 
In summary, in the subsequent empirical process, in addition to considering the explanatory variable of investor attention represented by Baidu Index, this paper also introduces relevant variables that can reflect company size, market risk and stock book value. As a generalization and discussion of the three-factor model.

1) Stock market value (Cap)

This paper selects the market value of individual stocks to reflect the size of listed companies, referred to as market value. Since the market value of coal companies is relatively large, this paper sets its unit to 10 billion in empirical research.

Market value of individual stocks $(\mathrm{Cap})=$ market price per share $\times$ total number of shares issued

2) Net assets per share (Nav)

Net assets per share, also known as stock book value or net stock value, is the value of the actual assets represented by each share.

Net assets per share $(\mathrm{Nav})=$ (company net assets - book value of preferred shares)/number of ordinary shares outstanding

3) Market Yield (MReturn)

The variable is the increase or decrease of each trading day of the CSI 300 Index, which is the index of the closing price of the day's index relative to the closing price of the previous trading day.

Market return rate $($ MReturn $)=($ closing price of the day - closing price of the previous trading day)/closing price of the previous trading day $\times 100 \%$

\subsection{Empirical Model Construction}

The Capital Asset Pricing Model (CAPM) proposes that the return on investment of assets will be affected by market risks, and the return on investment of each financial asset has a certain proportional relationship with market risk [9]. This model has been widely used in financial markets, but as mentioned earlier, the theory is based on the market hypothesis. There are many shortcomings in the explanation of the excess return on financial assets. Therefore, it was questioned by scholars such as Fama and French. In 1992, Fama and French conducted a statistical study on the stock returns in the US stock market. The results show that the beta value of the stock market does not explain the difference in the return of different stocks, and the market value, book value ratio, and price-earnings ratio of listed companies can explain the difference in stock returns [10]. In the empirical research, they mainly proposed three factors: market asset portfolio $\left(R_{m}-R_{f}\right)$, market capitalization factor (SMB), and book value-to-market ratio factor (HML). The three-factor model constructed by Fama-French (1993) is as follows:

$$
E\left(R_{i, t}\right)-R_{f, t}=\alpha+\beta_{1}\left[E\left(R_{r m, t}-R_{f, t}\right)\right]+\beta_{2} E\left(S M B_{t}\right)+\beta_{3} E\left(H M I_{t}\right)+\varepsilon_{i, t}
$$

where $R_{f, t}$ is the risk-free rate of return at time $\mathrm{t} ; R_{r m, t}$ is the market combined rate of return at time t; $R_{i, t}$ is the rate of return of asset $i$ at time $t$; $E\left(R_{r m, t}-R_{f, t}\right)$ represents the risk premium, $S M B_{t}$ represents the combined 
market value factor yield at time $\mathrm{t}$, and $H M I_{t}$ represents the combination of the book market value ratio factor simulated at time t. rate of return. Among them, $\beta_{1}, \beta_{2}$ and $\beta_{3}$ are the coefficient values of the three factors in the model, respectively.

Fama-French (1993) used a constant beta value in constructing a three-factor model [11]. In this article, we have optimized and improved the beta value, using the stock market value (Cap) of the listed company of coal and its corresponding net asset per share (Nav) instead of the $S M B_{t}$ and $H M I_{t}$. At the same time, because this article studies the impact of investor attention on the market performance of coal listed companies, there are many heavyweights in the listed companies in the coal industry, which will have a certain impact on the overall market trend. Therefore, this paper chooses to use Market yield (MReturn) to represent the market portfolio yield. Finally, in order to simplify the expression of the three-factor model, the risk-free rate of return $R_{f, t}$ is incorporated into the a term, and a new three-factor model is obtained. The specific formula is as follows:

$$
\operatorname{Return}_{i, t}=\alpha+\beta_{0} \text { Attention }_{i, t}+\beta_{1} \operatorname{Cap}_{i, t}+\beta_{2} \operatorname{Nav}_{i, t}+\beta_{3} \operatorname{MReturn}_{i, t}+\varepsilon_{i, t}
$$

\section{Empirical Analysis}

\subsection{Stationarity Test}

The research objects selected in this paper are 17 listed companies in the coal industry from January 1, 2018 to December 31, 2018. The data selected during the model establishment are panel data, because the panel data has both time and cross-section characteristics. In order to avoid the use of time series to generate pseudo-regression problems, it is necessary to perform a stationarity test on the data to ensure that the distribution of time series variables does not change with time. The stationarity test in this paper uses the unit root test. The unit root test refers to whether there is a unit root in the test sequence. The unit root refers to the unit root process. If there is a unit root process in the sequence, then the sequence is a non-stationary time series. There will be a "pseudo-regression" in the regression analysis, and the result produced at this time is invalid.

The stationarity test in this paper uses the LLC test method in the unit root test method. The variables involved in this section mainly include the return rate, the excess return rate (AReturn), the absolute value of the excess return rate (AReturnabs), and the stock volume. (Volume), stock turnover rate (Turnover), investor attention (Attention), individual stock market value (Cap) and market return rate (MReturn), the unit root test for the above indicators.

By using the Stata software for the stability test of all the variables except the net variable per share (Nav) of 17 listed coal companies, it can be seen from the test results Table 2 that all variables passed the $1 \%$ significance level test. Therefore, the time series selected in this paper is stable, there is no pseudo-regression phenomenon, and further regression analysis can be performed. 
Table 2. Panel data LLC unit root test result.

\begin{tabular}{ccc}
\hline variable & Adjusted $t$ & Prob 值 \\
\hline Return & $-47.9883^{* * *}$ & 0.0000 \\
AReturn & $-44.4180^{* * *}$ & 0.0000 \\
AReturnabs & $-33.2382^{* * *}$ & 0.0000 \\
Volume & $-13.3578^{* * *}$ & 0.0000 \\
Turnover & $-13.3572^{* * *}$ & 0.0000 \\
Attention & $-10.7399^{* * *}$ & 0.0000 \\
Cap & $-3.4858^{* * *}$ & 0.0002 \\
MReturn & $-40.7178^{* * *}$ & 0.0000 \\
\hline
\end{tabular}

***, ${ }^{* *},{ }^{*}$ Representing significant confidence levels of $1 \%, 5 \%$, and $10 \%$, respectively.

\subsection{Correlation Analysis}

In order to have a preliminary understanding of the relationship between the variables in the model, this paper tests the correlation between the explanatory variables and the explained variables before the regression analysis. The test results are shown in Table 3.

It can be seen from the correlation test results in Table 3 that the explanatory variable investor attention (Attenion) and the absolute value of the variable excess return rate (AReturnabs), stock volume (Volume), stock turnover rate (Turnover), individual stock market Both the value (Cap) and the net asset per share (Nav) are positively correlated. Among them, the correlation coefficient between return and return (AReturn) and market return (MReturn) is large, because the calculation of excess return is through the difference between stock return and market return. The way the sample is obtained, so the correlation coefficient between the sample stock return rate and the excess return rate and the market yield rate is higher. Compared with the stock return rate, the correlation coefficient between the investor's concern (Attenion) and the excess return rate (AReturn) is 0.0045 , and the correlation coefficient with the absolute value of the excess return rate (AReturnabs) is 0.3253 , which is greater than the investor's concern and stock returns. Therefore, in the regression, we finally choose the excess return rate and excess return rate absolute value model to explore the impact of investors' attention on stock returns.

\subsection{Linear Regression Analysis}

According to Hypothesis 1: Investor attention is positively correlated with the stock returns of coal listed companies. Regression analysis of the investor's attention and the absolute value of the sample company's stock excess return rate and the sample company's stock excess return rate, taking into account the fixed effect in a single stock and the time-fixed effect of the entire year of 2018, the model is adjusted The final result is shown in Table 4. 
Table 3. Variable correlation coefficient table.

\begin{tabular}{|c|c|c|c|c|c|c|c|c|c|}
\hline & Return & AReturn & AReturnabs & Volume & Turnover & Attention & Cap & $\mathrm{NaV}$ & MReturn \\
\hline Return & 1 & & & & & & & & \\
\hline AReturn & $0.7877^{* * *}$ & 1 & & & & & & & \\
\hline AReturnabs & $-0.0933^{\star * *}$ & 0.0059 & 1 & & & & & & \\
\hline Volume & $0.0510^{* * *}$ & $0.0890^{* * *}$ & $0.4248^{\star * *}$ & 1 & & & & & \\
\hline Turnover & $0.0330^{\star *}$ & $0.0837^{\star * *}$ & $0.4676^{* * *}$ & $0.5450^{* * *}$ & 1 & & & & \\
\hline Attention & -0.0061 & 0.0045 & $0.3253^{* * *}$ & $0.5391^{* * *}$ & $0.4625^{* * *}$ & 1 & & & \\
\hline Cap & 0.0092 & 0.0099 & $0.0265^{\star}$ & $0.0356^{* *}$ & $-0.0426^{* * *}$ & $0.4093^{* * *}$ & 1 & & \\
\hline $\mathrm{Nav}$ & 0.0046 & 0.0058 & $0.0389^{* *}$ & $-0.0704^{\star * *}$ & $-0.0534^{* * *}$ & $0.3600^{\star * \star}$ & $0.6918^{* * *}$ & 1 & \\
\hline MReturn & $0.6077^{\star * \star}$ & -0.0106 & $-0.1591^{\star * \star}$ & -0.0320 & $-0.0544^{* * *}$ & -0.0157 & 0.0022 & 0.0000 & 1 \\
\hline
\end{tabular}

${ }^{* * *},{ }^{* *},{ }^{*}$ Representing significant confidence levels of $1 \%, 5 \%$, and $10 \%$, respectively.

Table 4. Hypothesis 1 regression result table.

\begin{tabular}{ccccc}
\hline & Attention & Cap & Observations & Adj. $R^{2}$ \\
\hline Hypothesis 1 & $0.3765^{* * *}(0.0372)$ & $-0.1018^{* * *}(0.0209)$ & 4114 & 0.5016 \\
\hline
\end{tabular}

${ }^{* * *},{ }^{* *},{ }^{*}$ Representing significant confidence levels of $1 \%, 5 \%$, and $10 \%$, respectively.

The regression results in Table 4 reveal that the investor's attention is significantly positively correlated with the stock returns of coal listed companies, i.e., Hypothesis 1 is confirmed. Since the number of proxy variables Baidu Index of investors' attention is large, the previous definition of the variable is set to 100 , and the rest of the variables are calculated as a percentage. The regression coefficient of investor attention obtained through empirical analysis is 0.3765 , which indicates that the investor's interest rate for each stock will increase by 0.3765 percentage points.

According to Hypothesis 2: Investor attention is positively correlated with the stock flow of coal listed companies, and the regression analysis of investor attention and sample company stock turnover and sample company stock turnover rate.

Firstly, the model is used to linearly study the correlation between the investor's attention and the sample company's stock volume. It also uses the fixed-price effect and the time-fixed effect to test the market return rate (MReturn) of the control variable that is not affected by the time series. After the constant term intercept term, the regression results are shown in Table 5.

The regression results in Table 5 reveal a significant positive correlation between investor concerns and stock trading volume of coal listed companies. For investors to increase the attention of each unit by one unit, the stock will increase the volume of 0.0790 units. This conclusion provides a strong proof of Hypothesis 2-the assumption that investor concerns are positively correlated with the liquidity of coal listed companies' stocks. 
Next, a linear regression is performed on a model that studies the correlation between investor attention and sample company stock turnover. It also uses the fixed-price effect and the time-fixed effect to test the market return rate (MReturn) of the control variable that is not affected by the time series. After the constant term intercept term, the regression results are shown in Table 6.

The regression results in Table 6 reveal a significant positive correlation between investor attention and stock exchange rate of coal listed companies. Investors will increase the turnover rate of $0.2952 \%$ for each additional unit of interest in a stock. Based on the conclusion of the previous section, the two indicators of stock liquidity of coal listed companies are significantly positively correlated with investor attention, which can confirm that hypothesis 2 is established.

\section{Conclusions and Suggestions}

\subsection{Conclusions of Analysis}

The article uses Baidu Index as a research index to study the relationship between investor attention and market performance of coal listed companies. This paper takes 17 listed companies in each industry in China as the research object, and collects Baidu search data and stock market data from January 1, 2018 to December 31, 2018 for empirical analysis. The results show the hypothesis 1-investment: the degree of attention is positively correlated with the stock return rate of coal listed companies. Hypothesis 2 -Investor attention is positively related to the stock liquidity of coal listed companies.

1) Analysis of the return results and causes of investor attention and stock returns of coal listed companies

It can be seen from the above regression results that Hypothesis 1 is established, and the higher the investor's attention, the more active the market trading of individual stocks, and the higher the stock return rate.

This may be because in reality, high-interest stocks can always attract more investors to invest in them, and good news is more likely to attract investors' attention, prompting people to conduct Baidu search, so higher investment. The attention has generated more net purchases, which has positively contributed to the stock price.

Table 5. Hypothesis 2a regression result table.

\begin{tabular}{ccccc}
\hline & Attention & Cap & Observations & Adj. $R^{2}$ \\
\hline Hypothesis 2a & $0.0790^{* * *}(0.0047)$ & $-0.0242^{* * *}(0.0019)$ & 4131 & 0.7965 \\
\hline
\end{tabular}

$* * *,{ }^{* *},{ }^{*}$ Representing significant confidence levels of $1 \%, 5 \%$, and $10 \%$, respectively.

Table 6. Hypothesis $2 \mathrm{~b}$ regression result table.

\begin{tabular}{ccccc}
\hline & Attention & Cap & Observations & Adj. $R^{2}$ \\
\hline Hypothesis 2b & $0.2952^{* * *}(0.0149)$ & $-0.0954^{* * *}(0.0088)$ & 4131 & 0.7383 \\
\hline
\end{tabular}

***, ${ }^{* *},{ }^{*}$ Representing significant confidence levels of $1 \%, 5 \%$, and $10 \%$, respectively. 
2) Analysis of the return results and causes of investor attention and stock liquidity of coal listed companies

It can also be seen from Table 2 that Hypothesis 2 is also established. The higher the investor's attention, the higher the stock liquidity of coal listed companies.

This may be because when stocks are highly concerned by the market, it will lead to behaviors that drive attention to trading. Investors buy and sell stocks in large quantities, which increases the trading volume and turnover rate of stocks, and is more likely to lead to excessive trading. Therefore, when investors choose stocks to buy from the stock market, they are more inclined to buy stocks that can attract more investors' attention. When stocks' attention increases, this net buying behavior will enhance stock liquidity, verifying hypothesis 2 .

\subsection{Suggestions}

1) Improve the disclosure mechanism and strengthen institutional supervision

Regulators should establish and improve the information disclosure mechanism of China's stock market as soon as possible, and improve the current information asymmetry in the market, so that different types of investors have the same fairness in obtaining information disclosed by listed companies. At the same time, it is necessary to regulate the information exchange behavior of securities practitioners and protect the legitimate rights and interests of investors, especially small and medium investors.

2) Improve business capability and protect investor interests

As a listed company, on the one hand, efforts should be made to improve its own operational capabilities. Operating according to law and operating with integrity are fundamental to the foothold and development of each listed company. On the other hand, listed companies should strictly implement the requirements for information disclosure and regulatory enforcement. It is necessary to focus on and manage investors' right to know, decision-making participation rights, and investment income rights, build and expand channels for communication between enterprises and small and medium-sized investors, improve the transparency of information disclosure and resolutely protect the legitimate rights and interests of investors.

3) Careful research, rational investment

As an investor, you should study professional knowledge, broaden your horizons, and improve your literacy. Before making investment decisions, conduct careful research, observe and analyze from multiple angles, make rational decisions, and eliminate blind follow-up. In addition, we must analyze our own ability to withstand risks, do psychological preparation and material preparation for risk taking, and then put into investment actions.

\subsection{Research Deficiency and Prospect}

In the field of financial behavior, investor attention has been a hot topic in re- 
cent years. However, how to construct a direct measure of investors' limited attention has been a persistent problem. Until the launch of Google trend and Baidu Index, people gradually realized the value of search data and mined the psychology and behavior of people hidden behind the data. This paper takes the Internet search data as a direct indicator to measure the attention of investors, and believes that the attention of investors represented by Baidu Index has a significant correlation with the market performance of listed coal companies, and can play a reference role. Since this paper is a preliminary study of applying Internet search data to market performance prediction of listed companies, there are still some deficiencies in the following aspects:

1) Due to the limitations of time and energy, this paper only studies the January 1, 2018-2018 on December 31 coal industry the market performance of listed companies, because all of the coal industry is cyclical stocks, this research did not prove the conclusion whether to apply for the cyclical stocks, on the whole stock market whether all the shares of listed companies are applicable.

2) Baidu Index is used to measure the attention of all investors in this paper. However, in fact, for different investors, they measure the attention in different ways. Some investors will use other search tools, such as Google Search, Sogou Search, etc. Therefore, this paper USES Baidu Index to measure the attention of all investors in this way will inevitably have some errors, resulting in measurement value is not completely accurate.

3) In reality, institutional investors seldom use search engines to obtain stock information of various companies. Internet search data mostly represent the attention of small and medium-sized investors, while the attention of institutional investors is less representative.

4) Baidu Index can only provide daily attention, but does not provide distribution and change information of attention in different periods of a day. Therefore, the research on hysteresis in this paper is also based on the data of individual stocks in the previous 1 to 3 days, and it cannot use high-frequency data for more microscopic research.

Based on the above deficiencies, I hope to optimize and explore the following aspects in the future research:

1) To expand the sample scope, we can investigate the stocks of listed companies in multiple industries and conduct horizontal comparison of the data of listed companies in different industries, so as to ensure comprehensive and reliable empirical results and make the research conclusions more applicable to the whole financial market.

2) In the era of big data, investors have more and more choices of search engines. In order to make up for the limitation of Baidu Index, the original search volume data can be weighted according to different search engines, so that the search data can more accurately measure investors' attention.

3) For different investor groups, categories can be divided according to some behavioral characteristics and measured separately to make the research results more practical and accurate. 
4) In terms of Internet data refinement, if Baidu Index cannot be achieved, social network data such as Weibo and other media company data can be fully mined for more detailed analysis and research.

\section{Conflicts of Interest}

The authors declare no conflicts of interest regarding the publication of this paper.

\section{References}

[1] James, W. (2010) The Principles of Psychology. 2nd Edition, Digireads.com, Overland Park.

[2] Barber, B.M. and Odean, T. (2008) All That Glitters: The Effect of Attention and News on the Buying Behavior of Individual and Institutional Investors. Review of Financial Studies, 21, 785-818. https://doi.org/10.1093/rfs/hhm079

[3] Hiller, S. (2014) The Export Promoting Effect of Emigration: Evidence from Denmark. Review of Development Economics, 18, 693-708. https://doi.org/10.1111/rode.12112

[4] Sheline, Y.I., Joseph, L., et al. (2010) Resting-State Functional MRI in Depression Unmasks Increased Connectivity between Networks Via the Dorsal Nexus [Medical Sciences]. Proceedings of the National Academy of Sciences of the United States, 24, 20-25. https://doi.org/10.1073/pnas.1000446107

[5] Grullon, G. and Ikenberry, D.L. (2010) What Do We Know about Stock Repurchases? Journal of Applied Corporate Finance, 13, 31-51. https://doi.org/10.1111/j.1745-6622.2000.tb00040.x

[6] Nielsen, A.M., DeCarvalho, et al. (2010) Investigation of an Onsite Wastewater Treatment System in Sandy Soil: Site Characterization and Fate of Anionic and Nonionic Surfactants. Environmental Toxicology \& Chemistry, 21, 2606-2616. https://doi.org/10.1002/etc.5620211212

[7] Aboody, D., Johnson, N.B. and Kasznik, R. (2010) Employee Stock Options and Suture Firm Performance: Evidence from Option Repricings. Journal of Accounting \& Economics, 50, 74-92. https://doi.org/10.1016/j.jacceco.2009.12.003

[8] Da, Z., Engelberg, J. and Gao, P. (2011) Internet Search and Momentum. SSRN Electronic Journal, 3, 12-44. https://doi.org/10.2139/ssrn.1785924

[9] Lau, M., Herdrich, G.H. and Karrer, N. (2013) Power Train Configuration Study on a Pulsed Plasma Thruster with State-of-the-Art High Current Monitors. 49th AIAA/ASME/SAE/ASEE Joint Propulsion Conference, San Jose, 14-17 July 2013, 1-9. https://doi.org/10.2514/6.2013-4122

[10] Herzog, B. (2012) Asset Prices and Google's Search Data. SSRN Electronic Journal, 4, 10-39. https://doi.org/10.2139/ssrn.2045766

[11] Ding, R. and Hou, W. (2015) Retail Investor Attention and Stock Liquidity. SSRN Electronic Journal, 37, 12-26. https://doi.org/10.1016/j.intfin.2015.04.001 